\title{
FROM AUTOPSY TO AUTONOMY IN WRITING CENTRES: POSTGRADUATE STUDENTS' RESPONSE TO TWO FORMS OF FEEDBACK IN A HEALTH PROFESSIONS EDUCATION MODULE
}

In post-apartheid South Africa, writing centres exist in almost every university to address the academic writing needs of students. At Stellenbosch University Writing Lab, writing consultants use collaborative learning and peer feedback in their work with writers in one-toone consultations. As part of a larger research project about how students in a Health Professions Education Master's degree responded to different types of feedback, our study focuses on whether the feedback received in a writing consultation compares to, or differs from, the feedback from the class group members. Our findings suggest that in general the students were open to interventions such as writing consultations. Furthermore, peer feedback from both a class group member as well as a writing consultant was experienced as useful. The study further shows that the consultants' approach to giving feedback was in line with the pedagogy practised in writing centres. The article concludes with measures that were implemented to address uncertainties identified in the study. We recommend that the purpose of consultations be clarified to lecturers, that consultations be integrated in the writing process before the assignment is marked and, to minimise role confusion, that consultants describe to students the way consultations work at the beginning of the consultation.

\section{Keywords}

Writing centres; writing consultations; peer feedback; postgraduate students; medical education

\section{INTRODUCTION}

In post-apartheid South Africa, writing centres have become part of the higher education landscape and most South African universities now have at least one writing centre (Archer \& Richards, 2011). Even though the institutional location, the funding model, the design and layout, the staff component, and the client list of these writing centres may differ, what they do have in common, are certain principles on which they build their practice. One of these principles is that writing is viewed and approached as a social practice - something that the writer does in collaboration with another party (Flower \& Hayes, 1981; Lunsford, 2008). Thus, all these writing centres share a pedagogy of individualised writing support in the form of one-to-one consultations.

At the heart of the writing centre practice and the one-to-one writing consultation is the writing consultant who acts as a critical reader and supportive collaborator to the writer (Harris, 1995; Ryan \& Zimmerelli, 2010). At the Stellenbosch University Writing Lab, the writing consultants are postgraduate students from various faculties at the University. These consultants are appointed on the basis of good writing skills and excellent interpersonal and communicative skills. They are not required to be language majors or language teachers, and receive substantial training about writing centre theory and practice. An important aspect of their training involves strategising about how to conduct conversations about writing, especially how to give effective feedback to students. Whereas feedback received from 
lecturers on written assignments tends to be directive, the feedback aimed at in writing centres is facilitative, formative and aims to empower students to develop their academic voices to become autonomous writers (Nichols, 2011a). This type of feedback has been described as 'feed-forward' because the purpose is developmental (Deyi, 2011: 47).

Our research formed part of a larger study that was a collaboration between the Writing Lab and a lecturer teaching the Educational Research for Change module in the M.Phil. Health Professions Education (HPE) programme. This is a postgraduate programme in the Medical and Health Sciences faculty and the students enrolled in the programme are all full-time practitioners in health sciences fields. In the HPE module, Educational Research for Change, the students reflect on and write about feedback as part of their development as future medical educators (Leibowitz, 2013). Our sub-study used the writers' reflections on the consultation with the writing consultant and the writers' reflections on feedback by another student in the module to analyse how the writers viewed the writing support received during the module.

As part of the module requirements, the students firstly received feedback from their lecturer on the assignment that they had written. Thereafter, they received two additional sources of feedback using the marked assignments - from one of their peers in the class group and then from a consultant at the Writing Lab. In their reflective reports, the students compared and analysed the different forms of feedback.

This article discusses the HPE students' reports about receiving feedback from two different types of peers and what emerged from these experiences. We examine whether, and in what way, students found that the feedback received in the writing consultation compared to or differed from the feedback from the class group member. In particular, the article focuses on the nature of the feedback that the students received from the Writing Lab consultants and whether the feedback of the consultants met the expectations of the writers.

\section{BACKGROUND TO THE STUDY}

To provide a background for the study, we firstly describe how the Writing Lab works, the services it provides, and the nature of the collaboration between the Writing Lab and the HPE programme. To further contextualise the study, we discuss peer feedback, especially the type of feedback provided in writing centres.

\section{Writing consultations at the Writing Lab}

Writing centres work on the basis that writing is contextual, social and collaborative (Flower \& Hayes, 1981; Lunsford, 2008). Writing is seen as a social action that requires writers to interact and collaborate with other partners such as writing consultants. This collaboration can help writers to identify and solve problems, lead to greater critical thinking, and a deeper understanding of others (Lunsford, 2008). Moreover, it 'engages the whole student and encourages active learning; it combines reading, talking, writing, thinking; it provides practice in both synthetic and analytic skills' (Lunsford, 2008: 95).

The core services that the Stellenbosch University Writing Lab provides to postgraduate students are writing consultations and academic writing workshops. The one-to-one writing consultation is a free service to all students. In the consultation, the consultants engage with students about their writing and act as critical readers and friends. The underlying principle here is the Vygotskyian one that knowledge is developed and learning occurs in collaboration 
with other people (Vygotsky, 1978) and the idea that any student could benefit from such a collaboration even if the consultant is from a different field of study. This type of conversation has been referred to as a 'collaborative talk' (Gillespie \& Lerner, 2008: 14). Furthermore, consultants acknowledge that the writers they work with have content knowledge in their fields. Thus the dynamic in the consultation is a reciprocal one where both parties contribute expertise (or some form of knowledge).

Affective issues around writing are equally important at the Writing Lab and because we work directly with writers, rather than only with texts, we train the consultants to be aware of this. We aim for a consulting relationship based on trust and empathy (Daniels \& Richards, 2011) because this can help a writer to develop a sense of self-efficacy (Lape, 2008). One of our aims is to help writers to 'feel safe enough to take risks in their writing' (McLeod, 1997: 2 ), and so we structure our consultation strategically towards this end. For instance, we establish rapport at the beginning of the consultation by introducing ourselves and using the students' names when we address them. We take an interest in their writing process and invite them to tell us about how they wrote their assignments, the types of challenges they faced and the decisions they made. We take care to acknowledge the amount of effort writers have taken with their work and to notice what they have done well. This makes us come across as less threatening and more approachable. It also allows the writers to feel heard (Nichols, 2011a). We are careful, for this reason, to maintain a neutral stance towards the writer's text and to avoid value judgements when responding to writing (Gillespie \& Lerner, 2008; Ryan \& Zimmerelli, 2010).

\section{Peer feedback in writing centres}

In writing centres, large emphasis is placed on the nature of the feedback so that the feedback received advances writing centre ethos and pedagogy. At the Writing Lab, the consultants undergo 30 hours of training, with certain training sessions focusing exclusively on feedback to writers, such as 'Consultation strategies: Giving effective feedback', 'Effective questions for consultations' and 'Feedback on consultations'.

With feedback in general, the person who gives feedback, the form, and the manner in which the feedback is given are factors that could impact on the way that students receive and value that feedback. The source of feedback can be a lecturer, a peer or a fellow student, and the form of feedback could include 'giving praise and encouragement, correcting, giving individual tutorials' (Ahmadian, Yazdani \& Ebadi, 2013: 220). In writing centres, feedback is given by writing consultants, and even though the consultants may be from different fields of study, it can be argued that they are also peers as they are also students (Lunsford, 2008; North, 1984).

In the case of peer feedback, collaboration is an essential component in the relationship between the giver and the receiver of the feedback. Peer feedback, grounded in sociocultural theory, has a strong social element (Ahmadian, Yazdani \& Ebadi, 2013), and so students have to interact with each other in order to achieve the outcomes of the session. In such a collaboration, students discuss their work with a peer who asks critical questions, and provides feedback on how the text may be improved (Hu, 2005). This resonates strongly with the type of feedback given in writing centre consultations.

Additionally, the effectiveness of feedback depends on features of its quality. Effective feedback must include 'feed up', feed back' and 'feed forward' (Hattie \& Timperley, 2007: 86). In other words, feedback must consider where the writer is going, how to get there, and where to go next. In relation to writing centres, Deyi $(2011: 47)$ explains that '[w]hile 
mainstream academia often works with feedback; writing centres tend to work with feedforward'. Whereas feedback is often a one-way process from the lecturer to the student without any input from the student, writing centre feedback tends to be facilitative and meaning is negotiated through questions, probing or reflections. Such feedback comments will help students to understand reasons for a suggested change and help guide them to rework their texts on their own. Student writers also have the opportunity to explain their ideas further or correct the perceptions of the person giving feedback. This type of feedback may also have a better effect on learning as it allows writers to make choices and provides room to develop in different ways. This is in contrast to giving too many directive feedback comments which can be seen as criticism and give the impression that the consultant wants to control the writer's text (and ideas) (Underwood \& Tregidgo, 2006).

Furthermore, giving and receiving feedback is not purely a rational activity and emotions are involved. Carless (2006: 221) reasons that, since assignments are usually 'personal and individual activit[ies]', negative feedback could influence the student's 'self-perception' in a negative manner. He concludes that feedback is 'a social process in which elements, such as discourse, power and emotion, impact on how messages can be interpreted'. For this reason, writing centre consultants are trained in how to give both positive and negative feedback that is constructive and supportive. Research further shows that students prefer positive feedback such as praise and constructive criticism (Deyi, 2011; Lamb \& Simpson, 2011). However, Hattie and Timperley (2007: 97) argue that, for positive praise to be of value, it should also be 'accompanied by information about the processes or performance'.

\section{METHODOLOGY}

In the larger study, an action research methodology was followed (Leibowitz, 2012). This action research intervention was a response to address the problem of student writing in the HPE programme. Students' writing had not improved despite the programme committee experimenting with various interventions over several years and lecturers providing regular, detailed feedback to the students. The larger study was, therefore, developed as a different type of intervention aimed to 'stimulate the students' metacognitive functioning' regarding academic writing and to make them 'aware of their own writing strategies' (Leibowitz, 2013: 32). One of the aims invites students to think about the nature of feedback and to be more supportive of each other. To achieve this, the students were required to receive feedback on a marked assignment from a peer and have a consultation with a Writing Lab consultant. They were then expected to write a reflective report comparing the two types of writing feedback. Our part of the study analysed the students' reflective reports on the two kinds of peer feedback they received and allowed us to compare them.

\section{Participants}

The nine students in this study were a class group from the medical and allied health disciplines. All students in this class participated in the study. They were part-time students enrolled in a two-year postgraduate programme. Five of the students worked at universities while the other four conducted training in the health care sector. They were mature students who were used to being mentors, team leaders or educators. Eight were South African and one was Namibian. The group included eight women and one man. Five were white and four were black (Leibowitz, 2013). 


\section{Data sources and analysis}

Data sources: The students' reports

For the purposes of our research, we have used the parts of the students' reports that pertained to the students' experiences of receiving feedback from a class group member and from a writing consultant. All the reports were written in English, as that is the language of teaching and learning for the Master's programme, although it is not the first language of many of the writers.

Towards the end of the first year of the programme, the nine students submitted their reports by email to the primary investigator of the larger study. The primary investigator subsequently emailed the reports to the Writing Lab researchers. We stored the reports on our personal computers' hard drives under pseudonymous file names to protect the respondents' identities. The reports were not therefore accessible to anyone else and the data were protected from being seen by anyone other than us.

\section{Analysis: Conventional content analysis}

The questions we wanted to address were:

- How did the students describe and experience the feedback that they received from their class group member and that of the writing consultant?

- Were there clear differences and/or similarities between the two types of feedback?

- What did the students learn from the feedback?

We manually analysed the reports using conventional content analysis (Hsieh \& Shannon, 2005). First, we individually lifted out themes we found to be relevant to our research topic. Next, to ensure we were rigorous, we used iterative questioning and in-depth review of our research questions and criteria. This entailed comparing our sets of themes and discussing them in the light of what we had read in the rest of the reports, seen in the writing issues the students experienced and what we had experienced ourselves while working with the students in workshops and consultations. From this, we developed the list of themes so that they covered all the aspects we had agreed were important. Once satisfied with our list, we crosschecked the themes with the reports a final time to make sure we could justify their selection. In the course of writing up the article, we revisited our themes and refined them further. To support our analyses we use quotations from the students' reflective reports.

Informed consent from the participants was obtained by the project leader, Brenda Leibowitz. The larger research project was approved by the Health Professions Programme Committee and Stellenbosch University Faculty Research Ethics Committee.

\section{FINDINGS}

The following themes related to feedback emerged from our analyses of the reflective reports:

- Expectations about the role of the writing consultant

- Role of the marked assignment in receiving feedback

- Differences between class group member feedback and writing consultant feedback

- Benefits of receiving feedback and what the students say they learnt from the exercise 
These themes are discussed in the following section.

\section{DISCUSSION}

\section{Expectations about the role of the writing consultant}

How the students understood the role and purpose of different types of feedback determined which type of advice was valued more. It emerged that there was a degree of confusion and a lack of knowledge amongst some of the students about the role of the consultant and about what to expect from the consultation. Even though one of the students had 'no clue' of what would happen in a consultation, she had the expectation of receiving some form of 'coach[ing]' about her academic writing style. However, 'the consultant ... introduced the session by clearing all the assumptions she thought she had about the pending experience' and this enabled her to have a better understanding about how the consultation would work. Some students wanted the consultant to have read the text beforehand and expected email feedback afterwards. These students seemed to view the consultation as a 'teaching' session, even though our consultants are trained to deal with role confusion by explaining early in the consultation how the process works and what a writer can expect from a session. Possibly because of this, some of these students described the help as generic and superficial, as the consultants work with structure, argumentation and referencing, and not directly with the subject matter of the assignment.

A previous study (Chen, 2010) explored the perceptions of postgraduates about feedback from peers and from writing consultants. Chen's study showed that the writers were more cautious in accepting feedback from peers. However, their peer feedback was partly about English grammar and the writers (all ESL writers writing in English) did not consider their peers to be experts in this domain, while they considered the writing consultants to be English grammar experts and therefore accepted the latter's feedback more readily.

Most of the HPE students were also ESL writers; however, they had all been studying medical education for at least a year so they considered themselves and their class group members to have a level of expertise in that field. In addition, a certain amount of scepticism exists amongst practitioners in medical education about the efficacy of using non-medical educational concepts in medical education (Sandars, 2015). It may have been a considerable paradigm shift for the HPE students to realise that the intention of the consultations was to use a question and answer approach 'so that I can identify my own mistakes', as one writer described it in her reflection. By contrast, the students who understood the purpose of the consultation process as facilitation and a way of developing transferable writing skills valued the experience more.

\section{Role of the marked assignment in receiving feedback}

Working with a marked assignment impacted on the way feedback was received by the HPE students. According to the arrangements the HPE students would have their consultations with both the class group member and the writing consultant - on marked assignments. In practice, however, this was not the case as in some instances the students decided to use the unmarked assignments for feedback. As a group, these students held quite strong views about their work and some had even challenged their markers during the modules to justify the marks they had allocated. These writers held themselves to high standards and were often dissatisfied with anything less than perfection. Those who had been in academia or who were team leaders admitted to struggling with moving from being the one who knows, to being the student once again. 
Sometimes the unmarked assignment may have allowed the writers to feel they could have a second opinion on their work, independent of the given mark. One of the students explained her choice as follows: 'I wanted their opinion of the work uninfluenced by the remarks of the marker.' Possibly the consultant feedback was considered more objective if uninfluenced by the opinion of the lecturer. The lecturer had advised the class group about what to focus on when providing feedback to their peers and some writers might have experienced this as biasing.

Our experience of using lecturers' comments in consultation has been varied. In some cases, it can guide the consultant into focusing on aspects of the writer's work that most need attention, particularly if the consultant is from a different discipline than the writer. However, concentrating on lecturer feedback can also prevent consultants and writers from focusing on other issues that may be equally important but that the marker has not alluded to. Occasionally, the writer may find that he or she disagrees with what the marker has said. One student viewed the marked assignment as a 'deficit' and found difficulty 'reconcil[ing]' the feedback from her marker with the 'shortfall' in her marks. She initially thought that the 'problem' lay more with the marker than with her, and it was only when she heard that other students in the group had similar experiences that she felt better about her lower-thanexpected mark.

Whereas working with a marked assignment could be regarded as summative and therefore viewed as 'grade justification' by the writer (Underwood \& Tregidgo, 2006), the purpose of a writing centre consultation is always formative. Feedback may be more effective when used for formative improvement than summative marking (Underwood \& Tregidgo, 2006). It may have been that the students who wanted to work from 'clean' documents realised that doing this could help them develop their writing.

In addition, the students had never interacted with the consultants before. This had a distinct advantage for some: 'They had no previous knowledge of me which might prejudice their evaluation either way. I could therefore attach more credibility to their opinion.' Nonetheless, one student felt it was a wrong decision to have worked on a marked assignment as it 'biased' the feedback towards what the marker had focused on instead of providing additional feedback. Although at first confident and without apprehension, her perspective changed when she did not perform as expected. This led to her experiencing 'anxiety' and 'self-doubt' and she experienced the subsequent consultation as an 'autopsy'. This gives the impression that the assignment was dead and past saving. Possibly, had she had an opportunity to consult on her writing before the assignment was marked, she may have been able to make some changes to improve her work before submission. Her word choice may have reflected her biomedical paradigm, but may also have indicated her view of the objective of the consultation in general. Instead of seeing this as an opportunity to acquire skills and practices that could be transferred to future writing assignments, she possibly saw it as merely another place to receive criticism on something already finished.

\section{Differences between class group member feedback and consultant feedback}

\section{Power and authority}

Clear differences emerged about issues of authority, power and whose advice was valued. In their training, writing centre consultants are cautioned about matters of power and authority when they engage with other students about their writing. They are trained to build trust, to respect the writers and their texts, to be non-judgmental, and, in this way, to ensure that the writing centre remains a safe space (Nichols, 2011b). They are advised to listen and talk to the 
writer as a peer during the consultations, in other words, as 'someone who also brings experience and knowledge to the session' (Wulff, Henderson, Williams, Marshall, Saravia \& Aleksa, 2014: 7). Peer consultations, if handled appropriately, have the power to effect positive results, but equally, if approached without reflection or care, have the power to do much damage (Nichols, 2011a).

The findings also showed that the type of relationship the student had with the person providing the feedback influenced how feedback was received. For some, the class member was a friend and an equal with whom they felt themselves to be in competition. One student describes the peer feedback in this way: 'I found this feedback easy to accept because it was balanced, well-articulated and from people I viewed as having comparable abilities to mine, having participated in an equal task.' The peer (in this case, the class group member) was generally seen as the insider, who knew the writer and the content of the assignment. Another, however, found the class member's feedback to be 'very critical' and 'carr[ying] strong tones of emotion and negativity'.

In contrast, the students saw the Writing Lab consultants as outsiders, because they were not part of the class group or of the discipline. From a writing centre perspective, this is ironic because we see the consultants as peers in the sense that they are fellow students. As a 'stranger', the consultant was no threat to the writers in terms of their position in the class or in terms of emotional engagement. The same student continues: 'By contrast I cared more about what would emanate from the Writing Lab. I respected their 'authority' as it were and experience to discharge that function.' Another writer said that the 'informal and supportive attitude' of the consultants 'created a positive, relaxed atmosphere'. A third student describes the consultant's 'friendly and supportive attitude' leading to 'spontaneous self-expression and self-evaluation'.

Although we aspire to keeping the consultations as friendly and as informal as possible, some of the students viewed the consultations as more formal than the feedback sessions with their peers. This could be because the consultation was the first time they had met and interacted with the consultant, whereas they had a shared history with their class group that involved more than just their class group consultation. Citing Race (2010), one student observed that '[a]lthough the experience with the peer student was relaxed, it evoked anxiety in me. A faceto-face discussion can be experienced as personal and authoritative (Race, 2010).'

\section{Directive or facilitative feedback?}

Class group members provided both written and oral feedback in an informal way. This feedback was, however, mostly directive and tended to focus on content and technical issues. Because it focused mainly on the content of the assignment, its benefit was short term, and thus more focused on the product. Dowse and Van Rensburg (2011:170) suggest that, in postgraduate writing, the product seems to take 'precedence over process', as the main objective is to complete the research report. This then increases the tendency to be more directive in consultations. In our study, while advice from the HPE peer tended to be more directive, the students noted that the feedback of the writing consultant was more facilitative and focused on developing transferable skills. This was in line with the way consultants are trained to engage during consultations. In order to avoid creating the impression of wanting to control the writer's work, consultants guide the students to rework their texts on their own (Harris, 1995).

It is for such reasons that the type of feedback the Writing Lab consultants give tends to be in the form of questions or reflections (Brooks, 1991; Harris, 1992; Thompson \& Mackiewicz, 
2014). A student described this as 'an interview like form of feedback', elaborating that 'the consultant read the introduction' and 'questioned whether [the] title reflected the content of [the] assignment'. This fits our pedagogy at the Writing Lab, where we do not tell the writers what to do, but rather give them a chance to discuss their writing, re-engage with it and make new decisions about how to develop it. This type of engagement also helps the student to understand the reasons for suggested changes and to have an opportunity of filling in any gaps in their writing by explaining further to the consultant. This 'new' information can then be incorporated into the assignment if the student has not yet submitted. In this way, student writers gain confidence and develop autonomy. Another student referred to the 'open-ended questions' that the consultant asked to 'probe' and gain more insights into her understanding of the topic. She also found the consultant's feedback easy to understand but was disappointed that the short duration of the consultation did not provide opportunity for indepth analyses.

Some students found this type of feedback useful and valued the consultant as a facilitator: '[the consultant] can highlight what you already know so that you can write more effectively'. Moreover, under these circumstances, the consultant's lack of subject-specific knowledge could be an advantage, especially in an interdisciplinary field such as medical education. One student found herself 'explaining' what she was talking about and why. She saw that this was an indication to her that she had not expressed herself that clearly to an 'outside reader' and had assumed that her readers would know what she was talking about. Although she was not able to change an already-marked assignment, she was able to take this insight into future academic writing.

\section{Benefits of receiving feedback and what the students say they learnt from the exercise}

For many of the HPE students, receiving feedback was 'a new experience'. The students in general were positive about the consultations and some 'embraced this new experience enthusiastically and absorbed new knowledge readily'. As Chen (2010) discovered with her group of ESL postgraduates, some of the HPE students tended to view the consultants as 'very knowledgeable', 'experts' and 'experienced' people whose advice could be trusted. The particular type of input the consultants provided was described as 'valuable' and 'filling gaps'. The consultants were able to provide feedback that was easy to understand and one student described leaving the consultation 'with hope'. She began to realise that the consultation was 'a stepping stone to adapt to the discourse' - in other words that developing writing skills is a process in itself and that following this process is one way of becoming familiar with a different academic discourse.

Many of the students agreed that receiving the two kinds of feedback was valuable and could enhance learning. For one student, it was 'an exciting experience'; for another, 'potentially an ideal way to get feedback on any assignment'. One student discovered that 'both sources covered aspects not touched upon by the lecturer'. Another student enjoyed the feedback session with her peer and the consultant as an opportunity to learn a little more about herself, and about making assumptions.

The students also made some recommendations about the three-pronged feedback process in general. An 'open disposition' in the writer facilitates the acceptance and usefulness of feedback. Feedback 'should be couched neutrally and sensitively to avoid being taken as a judgment'.

Some of the students have been academics or instructors for some time and for some of them, receiving a low grade and then feedback based on that grade from a class group peer, was a 
new experience. One participant reflected about the issue as follows when she performed 'far below' what she had expected: 'I was surprised at having misjudged my capability and became self-conscious about making anyone else privy to it. I wondered how my partners' view of me would change in the light of my performance. It was a new experience.'

As academics involved in the field of medical education, this feedback exercise was valuable to these students in particular: 'Having the tables turned on me and being at the receiving end of feedback has been instructive in understanding the gravity of this responsibility.' Another student reported: 'It gave me a glimpse of what it meant to have one's sense of self-worth wrapped around one's doing rather than in one's being and where the intersection and or separation between the two lay.' One student experienced her consultation as 'the proverbial "aha" moment' with 'moments of crystal clarity'.

\section{CONCLUSION}

The analyses of the reflections about the two types and sources of feedback showed that there were lessons to be learnt for both the Writing Lab and the HPE students in their roles as educators. Because the group was small (numbering only nine students), it is premature to draw generalised conclusions about what we saw and we took this into account when working with the data.

The findings indicated that in general the students in this study were open to interventions such as writing consultations. Furthermore, feedback from both a writing consultant as well as a class group member was seen as valuable and useful. From their reflections, it also seemed as if the students gained different kinds of knowledge from the two sources of feedback respectively. Receiving feedback to facilitate the learning of their own students was one of the benefits for the students in this research project. However, these writers were studying ways of approaching education in their field and it may have been that the professional background of writers could have influenced the way they received feedback or were open to interventions such as writing consultations.

Regarding the role of the consultants, our study showed that the consultants' approach to giving feedback was in line with their training and the pedagogy practised in writing centres. The strategies adopted during consultations were facilitative and supportive, and feedback given focused mostly on the higher order issues in writing.

This research has allowed us to address some of the writing issues that were identified as problematic to the students and to further develop our practices. Our goal with feedback is developmental and so we prefer to be part of a formative process and not to be seen as punitive or doing an autopsy. To this end, we now also try to clarify the purpose of consultations to lecturers and negotiate that the consultations be integrated in the writing process and not an intervention that happens at the end after the assignment has been marked. We furthermore actively encourage our consultants to briefly describe to students the way consultations work at the beginning of the consultation to minimise role confusion. In this way then, lecturers and writers can derive maximum benefit from consultations. 


\section{REFERENCES}

AHMADIAN, M, H YAZDANI, \& S EBADI. 2013. On the effects of peer feedback and teacher feedback on Iranian English language learners' writing ability. International Journal of English Language and Literature Studies, 2(4):220-238.

ARCHER, A \& R RICHARDS. 2011. Introduction: Writing centres as alternate pedagogical spaces. In Archer, A \& R Richards (Eds.). Changing spaces: Writing centres and access to higher education. Stellenbosch: Sun Press. 5-16.

BROOKS, J. 1991. Minimalist tutoring: Making the student do all the work. Writing Lab Newsletter, 15(6):1-4.

CARLESS, D. 2006. Differing perceptions in the feedback process. Studies in Higher Education, 31(2):219-233.

CHEN, CW. 2010. Graduate students' self-reported perspectives regarding peer feedback and feedback from writing consultants. Asia Pacific Education Review, 11:151-158. DOI 10.1007/s 12564-010-9081-5

DANIELS, S \& R RICHARDS. 2011. 'We're all in this thing together': An equitable and flexible approach to language diversity in the Stellenbosch University Writing Lab. In Archer, A \& R Richards (Eds.). Changing spaces: Writing centres and access to higher education. Stellenbosch: Sun Press. 33-44.

DEYI, S. 2011. Feedback or feedforward? Implications of the language used in giving feedback on students' writing. In Archer, A \& R Richards (Eds.). Changing spaces: Writing centres and access to higher education. Stellenbosch: Sun Press. 47-58.

DOWSE, C \& W VAN RENSBURG. 2011. 'Conversations' with postgraduate writers: Understanding the role of the peer tutor. In Archer, A \& R Richards (Eds.). Changing spaces: Writing centres and access to higher education. Stellenbosch: Sun Press. 159176.

FLOWER, L \& JR HAYES. 1981. A cognitive process theory of writing. College Composition and Communication, 32(4):365-387.

GILLESPIE, P \& N LERNER. 2008. The Longman guide to peer tutoring (2nd ed.). New York: Pearson Longman.

HARRIS, M. 1992. Collaboration is not collaboration is not collaboration: Writing center tutorials vs. peer response groups. College Composition and Communication, 43(3):369-383.

HARRIS, M. 1995. Talking in the middle: Why writers need writing tutors. College English, 57(1):27-42.

HATTIE, J \& H TIMPERLEY. 2007. The power of feedback. Review of Educational Research, 77(1):81-112.

HSIEH, HF \& SHANNON, S. 2005. Three approaches to qualitative content analysis. Qualitative Health Research, 15(9):1277-1288. DOI 10.1177/1049732305276687

HU, G. 2005. Using peer review with Chinese ESL student writers. Language Teaching Research, 9(3):321-342.

LAMB, S \& Z SIMPSON. 2011. Students' expectations of feedback given on draft writing. Per Linguam, 27(1):44-55. DOI 10.5785/27-1-97.

LAPE, N. 2008. Training tutors in emotional intelligence: Towards a pedagogy of empathy. Writing Lab Newsletter, 33(2):1-6.

LEIBOWITZ, B. 2013. Attention to student writing in postgraduate Health Science Education: Whose task is it - or rather, how? Journal of Academic Writing, 3(1):30-41.

LEIBOWITZ, B. 2012. Transitions to educational research amongst postgraduate Health Science students. Unpublished research protocol. Stellenbosch University. 
LUNSFORD, A. 2008. Collaboration, control, and the idea of a writing center. In Barnett, RW \& JS Blumner (Eds), The Longman guide to writing center theory and practice. New York: Pearson Education. 92-99.

MCLEOD, SH. 1997. Notes on the heart: Affective issues in the writing classroom. Carbondale: Southern Illinois University Press.

NICHOLS, P. 2011a. A snowball in Africa with a chance of flourishing: Writing centres as shifters of power in a South African university. In Archer, A \& R Richards (Eds), Changing spaces: Writing Centres and access to higher education. Stellenbosch: Sun Press. 91-99.

NICHOLS, P. 2011b. Student culture and cultural change: A manifesto for writing praxis in a South African writing centre. In Archer, A \& R Richards (Eds.). Changing spaces: Writing centres and access to higher education. Stellenbosch: Sun Press. 19-29.

NORTH, S. 1984. The idea of a writing center. College English, 46(5):433-446.

RACE, P. 2010. Making learning happen: A guide for post-compulsory education. London: Sage Publications.

RYAN, L \& L ZIMMERELLI. 2010. The Bedford guide for writing tutors (5th ed.). Boston: Bedford St Martins.

SANDARS, J. 2015. The challenge of feedback-insights from non-medical educational research. International Journal of Medical Education, 6:1-3. DOI: 10.5116/ijme.5489.eacb

THOMPSON, I \& J. MACKIEWICZ. 2014. Questioning in writing center conferences. The Writing Center Journal, 33(2):37-70.

UNDERWOOD, JS \& AP TREGIDGO. 2006. Improving student writing through effective feedback: Best practices and recommendations. Journal of Teaching Writing, 22(2):7397.

VYGOTSKY, L. 1978. Mind in society: The development of higher psychological processes. Boston: Harvard University Press.

WULF, A, A HENDERSON, C WILLIAMS, L MARSHALL, L SARAVIA \& V ALEKSA. 2014. To be a peer: An introduction to writing center theory and practice. Chicago: University of Illinois.

\section{BIOGRAPHICAL NOTES}

Sharifa Daniels is the Afrikaans Head of the Stellenbosch University Writing Lab. Her research interests are writing centres and diversity, identity, inclusion, and multilingualism. She has published in South African Journal of Higher Education and Per Linguam and is coeditor of Writing Centers and Disability. E-mail address: sdaniels@ sun.ac.za

Rose Richards is the English Head of the Stellenbosch University Writing Laboratory. Her research includes autoethnography, identity studies, illness narratives, and teaching writing. Some of her writing has appeared in Kunapipi: Journal of Postcolonial Writing, Qualitative Health Research, and South African Journal of Higher Education. Email address: rr2@sun.ac.za 